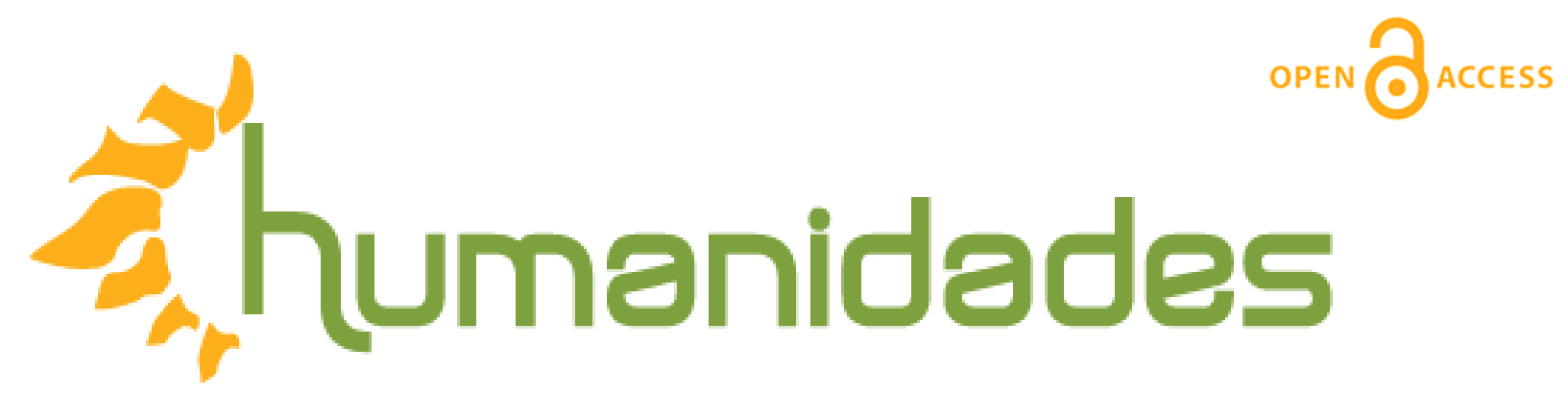

Revista de la Escuela de Estudios Generales, Universidad de Costa Rica

Enero-junio, 2017 •Volumen 7, número 1 • EISSN 2215-3934•pp. 1-11

\title{
Carta editorial
}

DOI: http://dx.doi.org/10.15517/h.v7i1.27687

\section{Ángel Ocampo Álvarez}

Doctor, profesor Catedrático en la sección de Filosofía y Pensamiento de la Escuela de Estudios Generales de la Universidad de Costa Rica.

Correo electrónico: angelocampoalvarez@ gmail.com 
Con el símbolo del ave de Minerva se ha pretendido -en particular a partir de Hegel- establecer la función de la filosofía, del conocimiento, de ese instrumento desarrollado por el ser humano para aprehender la realidad; en particular, la realidad histórica.

La capacidad de ver -conocer- en la oscuridad de la noche es la cualidad del búho que esta interpretación privilegia. Valioso aporte porque el ver supone la iluminación que suprime la obscuridad -ignorancia-. Se advierte ahí mismo que al señalar Hegel la función del conocimiento, establece también en ese instante, inevitablemente, los alcances, las posibilidades del conocimiento; en términos kantianos, los límites de lo que le está permitido conocer de la historia al ser humano.

No obstante, la metáfora de la noche (penumbras y sombras), implícita en los fundamentos o premisas desde los que ensambla este conocer sus categorías, construye una atmósfera que condiciona (posibilita o niega) la capacidad del conocimiento. Se considera que la noche es el ambiente propio de la calma, la quietud; esto es, el momento aquel que sucede al movimiento, aquel en el que la acción ha finalizado, en el que la obra ha concluido y ha caído el telón. Esta metáfora asimismo condiciona el conocimiento, al referir una realidad pasada a la que ya nada le afecta: el día ya ido. Se trata de una realidad a la que se le atribuye el carácter de cerrada, finita, consumada, en definitiva, muerta. Además, el ave de Minerva funda el conocer en un supuesto afuera 
de la realidad -el día-, en la no-realidad -la noche-. Finalmente, lo funda también en la soledad carente de relaciones, en un individuo solitario que la genialidad de su penumbra discierne, ya sin capacidad para intervenir, de ser partícipe de la realidad; el búho en la noche -el sujeto cognoscente- es un ave solitaria que tiene mutilada su capacidad de acción sobre lo que ve.

Así, esta tesitura reduce el conocimiento a una descripción -o justificación- de la realidad de las acciones que ya han tenido lugar y que se empiezan a extinguir como el día en el ocaso. Al llegar el fin, todo está cerrado, ya nada resta por hacer, solo describir, reflexionar -contemplar, según Aristóteles-; puede que lamentar o incluso celebrar, quizás justificar pero nunca transformar. La realidad finalmente se convierte en un pesado fardo que aplasta y cosifica; ese cúmulo de impotencia resulta que resulta ser el sujeto, existe como una hoja seca arrastrada por el torbellino recurrente de lo mismo, al cual llama fatídicamente destino.

Las limitaciones de este solitario búho nocturno pueden superarse -llevarse a una realidad superior-, al advertir que el conocer es también una acción. Este punto de partida en la compresión de la realidad permite caer en cuenta de que el conocer (como acción) es una acción más que, inserta junto con otras acciones, conforman la realidad; es por tanto una cualidad que acompaña al movimiento. Lo fundamental de esta advertencia reside en que al considerar la realidad abierta y no cerrada, dinámica y no inmutable a perpetuidad, el 
análisis de las acciones como fundamento de realidad, abre o posibilita el conocer las otras posibilidades que la realidad contiene y ante las cuales el ave de Minerva es ciega. La realidad trasciende lo fenoménico. Es la acción la que abre o muestra las posibilidades de la realidad. Ahora se hace evidente que el conocimiento no está irremisiblemente encadenado a lo establecido.

El conocer muestra o visibiliza -ilumina- la alteridad negada, los distintos caminos a otros mundos posibles y deseables en la medida en que realizan lo que el mundo establecido niega. Es en esta utopía o esperanza en donde emergen las categorías que permitirían una comprensión nueva y emancipadora de las sombras o las cadenas del presente. Ahí está, en ese futuro trascendente, que no es un mero desarrollo de lo que la realidad ya es, la comprensión adecuada de este presente que ya es historia para ese futuro trascendente. Así, el futuro trascendente se convierte en un mundo posibilitado por la acción presente, que aún no es y nunca será. A la realidad establecida, el presente, que conduce a ser pesimistas, se contrapone el deber de la esperanza fundada en la voluntad y en el acto creador, no en la simple innovación; pues se trata de un mundo o una realidad tan solo posible, deseable quizá, pero no inevitable.

Pese a su inaceptable y ciega determinación, el ave de Minerva está erigida sobre un acertado y rescatable principio: las limitaciones ineludibles del conocimiento. (Al fin y al cabo, no deja de ser un producto humano). A 
diferencia de la consideración mítica que tiene en el conocer un dictado de un mundo divino, la conciencia ahora puede reconocer que la aprehensión y el discernimiento humano de la realidad, el conocimiento, está claramente acotado. En particular, por una limitación que hoy golpea fuertemente la capacidad de comprensión del ser humano en su presente, que nos impide ser plenamente contemporáneos de nosotros mismos: el condicionamiento histórico, impronta de la cual el conocimiento no se libra totalmente. No obstante, el conocimiento no está condenado a las categorías del pasado. La conciencia puede enfrentar el presente desde la conciencia del futuro trascendente.

Esta misma época de la que somos testigos y actores en alguna y diferenciada medida, hoy no cuenta con una explicación satisfactoria de la realidad histórica; escasamente se cuenta con algunos señalamientos fragmentados. Señal de ello es el asombro y hasta la incredulidad que provocan los acontecimientos históricos recientes. Las predicciones se equivocan insistentemente. La globalización se cierra, las fuerzas revolucionarias se comportan conservadoramente, la tecnología debilita el ya frágil cordón umbilical que todavía ataba al ser humano con la naturaleza (dejando este débil tejido en serio peligro), se acelera la colonización -entiéndase bien, colonización- del espacio; una humanidad mayormente compenetrada materialmente se distancia hasta el solipsismo 
espiritualmente. No se cuenta aún con categorías que permitan una adecuada comprensión de la realidad presente.

Sin embargo, algunas categorías parecen ser suficientes para comprender que, como lo dijera I. Wallerstein, no estamos en el principio del fin, sino en el fin del principio. No iniciamos la decadencia de una época, sino la finalización del tránsito a otra. El parto se ha consumado y no se conoce bien la criatura nacida. Asistimos a una época que ya está plenamente instalada y que no comprendemos a plenitud. Sabemos muy poco de esta vertiginosa época que las fuerzas dominantes en la humanidad han provocado. Ahora sí se enfrenta la humanidad al conflicto de haber desatado fuerzas que es incapaz de controlar. El riesgo actual es que las fuerzas que ha generado el ser humano (y que le otorgan tanto poder) lo hagan, paradójicamente, impotente ante estas. En ese sentido, peligra que acaben exterminándolo, lo cual, hasta donde sabemos, sería la primera vez que ocurra: la autoexterminación de una especie, su suicidio.

En esta atmósfera, sale a la luz el primer número, del año 2017, de la Revista humanidades. Este número, que forma parte de nuestro séptimo volumen, consta de ocho artículos, los cuales integran cuatro de nuestras secciones. La primera de estas, Desde la cultura y el arte, presenta el artículo "El proceso de iniciación en una práctica cultural. El caso de seguidores de Carlos 'Indio' Solari”, del investigador argentino Nicolás Aliano. Dicho trabajo es el 
resultado de una investigación que, desde una perspectiva biográfica de análisis, propone sistematizar el análisis del proceso de afiliación a una práctica cultural concreta en el mundo popular contemporáneo, a partir de los "relatos de iniciación" de los seguidores de un músico de rock argentino, Carlos "Indio" Solari.

De Alfonso López Pulido, esta misma sección presenta el artículo "Kairotanasia y ancianidad en la antigüedad clásica", el cual sostiene que esta cultura antigua no establecía una clara línea divisoria entre la kairotanasia (muerte oportuna) y el suicidio, así llamado hoy. Para ello recuerda algunos casos de suicidios de personajes históricos, la mayoría de ellos ancianos políticos, y muestra con algunas citas que, en su momento, cada una de estas muertes fueron valoradas como la puesta en práctica de la kairotanasia; esto es, la muerte autoinflingida cuando se considera que la vida ya no puede seguir disfrutándose con un mínimo de condiciones psíquicas y físicas que la hagan apetecible y digna de ser vivida.

Esta primera sección concluye con un artículo del profesor Francesc Calvo Ortega, "Las intimidades colectivas de la clase obrera. Vida urbana y cultura popular en las ciudades de principios del siglo XX". En este trabajo, el autor analiza la cultura de resistencia que, se supone, asume la clase obrera y que es traducida en procesos de reapropiación. Considera que el obrero reelabora, con otras finalidades, las estructuras y las normas sociales que le son 
impuestas. Sin embargo, el paso al acto de autonomía, como viene a significar esa reapropiación, está en función de los recursos que dispone y varía según la conciencia individual, el grupo familiar y la organización política de la cual el individuo puede formar parte. Se hace patente, pues, un nivel de autodeterminación, como margen para la libertad individual, que permitiría un tipo de "cambio interior" y que haría posible a cada cual resistir las normas y regular la intensidad y la combinación entre el ámbito de lo colectivo y el ámbito de lo privado. En este sentido, el autor considera que la moral colectiva se construye en este entorno en que el imaginario social articula un entramado de representaciones autónomas.

En la segunda sección, Desde el lenguaje, la comunicación y la literatura, Wilfredo José Illas presenta su investigación "Repensar el estatuto epistemológico de los estudios literarios a partir de la comprensión hermenéutica: Una visión de la investigación en literatura". El profesor Illas, a fin de encontrar un espacio dialógico, plantea una visión hermenéutica que estrecha la disposición conceptual del estudio literario con la disposición funcional de investigación en literatura, reconstruyendo una perspectiva fenomenológica-hermenéutica alrededor de dos propósitos: reconceptualizar el ejercicio de los estudios literarios desde una dimensión interpretativa que transversaliza su objeto y operatividad, suscitando una concepción más amplia para comprender los productos literarios desde la naturaleza estética que los constituye; y, dimensionar los posibles cruces o articulaciones 
epistémicas que se demarcan entre las entidades conceptuales teoría, crítica, análisis e historia literaria, en consonancia con las tramas procesuales que se plantean para la concretud de la investigación literaria. Esta experiencia escritural se sustenta fundamentalmente en los aportes de Walter Mignolo.

Esta sección, además, presenta un artículo de Juan Antonio González de Requena Farré: "Un iconotexto liminar. Análisis iconológico de los grafiti de firma", donde el autor analiza el grafiti de firma o tag, el cual podría considerarse un tipo de realización iconotextual propio de nuestro tiempo. El conflicto interpretativo sobre este formato de autoinscripción ha acarreado cierta polarización entre la condena irrestricta y la fascinación estética. En este trabajo se realiza una exégesis iconológica del grafiti de firma, basada en la propuesta de Panofsky: se exploran sus motivos y se reconstruyen algunas tradiciones que sustentan sus modos de significación, para concluir con una interpretación del trasfondo epocal y comprensión cultural que le da sentido.

Cerramos este apartado con "Ontología, funciones y discurso en el videojuego", trabajo llevado a cabo por el investigador Jesús Portillo Fernández. El autor analiza la relación ontológica de los escenarios del videojuego, la realidad física y la interactividad del usuario en ambos planos; las características de los personajes que puede encarnar el jugador y las temáticas tradicionales de la filosofía y la literatura. A través del análisis de las modalidades oracionales, funciones lingüísticas y estructuras discursivas 
utilizadas por los jugadores (y la correlación entre estas y los objetivos del videojuego en línea), el estudio muestra que la transferencia contextual, en el sentido laxo, tiene lugar en las relaciones lúdicas en la red.

Ahora bien, la sección Desde la ciencia, la tecnología y el conocimiento presenta el artículo "Prolegómenos para una bioética desde el principio de alteridad”, en el cual Esteban J. Beltrán Ulate establece lo que llama un preludio o introducción a una bioética fundada en la alteridad, mediante el análisis del principio de alteridad. Lo anterior a partir de una visión antropológica basada en el reconocimiento del Otro, planteada por Emmanuel Lévinas.

Finalmente, en la cuarta sección, Desde las relaciones sociales, la Revista presenta un artículo sobre el impacto de la investigación arqueológica, específicamente, en el paraje El Tonelero de la localidad de Ramallo (Provincia de Buenos Aires, Argentina). "Cuando los límites importan: Dimensión pública e implicancias sociales del trabajo arqueológico" es un trabajo realizado por Virginia Salerno, Milva Umaño, Verónica Helfer, Alejandra Raies, H. César Pinochet, Mariano Darigo, Matías Warr y Mariano Ramos. Estos investigadores, adjuntos al Programa de Arqueología Histórica y Estudios Pluridisciplinarios (PROARHEP) y al Consejo Nacional de Investigaciones Científicas y Técnicas (CONICET), presentan el caso de un proyecto de investigación llevado a cabo en El Tonelero, donde iniciaron 
trabajos de arqueología histórica en el año 2012, como parte de un proyecto que estudia la Guerra del Paraná (1845 y 1846) desde una perspectiva pluridisciplinar. Así, los autores enfrentan la discusión sobre las implicancias de la construcción de una "dimensión pública" en torno a dicha investigación, e indagan el tipo de relaciones que confluyen con los contenidos históricos investigados desde que el equipo de arqueología se hizo presente en ese lugar. 